\title{
LA MODERNIDAD EN MENDOZA (1890- 1930): EL ENCLAVE CACHEUTA COMO TESTIMONIO DE MONTAÑA
}

\section{MODERNITY IN MENDOZA (1890-1930): CACHEUTA SETTLEMENT AS MOUNTAIN TESTIMONY}

DOI: https://doi.org/10.18861/ania.2019.9.2923

Arq. Ana María Villalobos

ORCID: https://orcid.org/0000-0002-3700-975X

Arq. Pablo Federico Ricardo Bianchi Palomares

ORCID: https://orcid.org/0000-0001-9941-3881 


\section{ARQ. ANA MARÍA VILLALOBOS}

Arquitecta. Especialista en Preservación Urbana y Restauración de Edificios Históricos, Universidad Nacional de Tucumán. Profesora titular en la Cátedra Historia de la Arquitectura y el Urbanismo 2 (turno A y B). - Facultad de Arquitectura, Urbanismo y Diseño, Universidad de Mendoza (Argentina). Doctorando en Doctorado en Arquitectura VII Cohorte-FAUD-UM (Argentina).

\section{ARQ. PABLO FEDERICO BIANCHI PALOMARES}

Arquitecto. Profesor adjunto de la Cátedra Arquitectura II-Taller de Integración Proyectual, Carrera Arquitectura, Universidad Nacional de Cuyo (Argentina). Doctorando en Doctorado en Arquitectura VII Cohorte-FAUD-UM (Argentina).

FECHA DE RECEPCIÓN: 30 de setiembre de 2019

FECHA DE ACEPTACIÓN: 13 de octubre de 2019

REGISTRO BIBLIOGRÁFICO: BIANCHI, P; VILLALOBOS, A. (2019). la modernidad en Mendoza (18901930): El enclave Cacheuta como testimonio de montaña. Anales de Investigación en Arquitectura, Vol. 9 (2), 69-88. 


\section{RESUMEN}

Esta investigación se basa en la detección de una vacancia en la lectura integral de los bienes culturales del tramo medio del río Mendoza, en la provincia homónima del centro oeste de Argentina. Las investigaciones actuales han avanzado de manera parcializada en el estudio de bienes históricos que consolidaron el territorio de la cordillera mendocina, lo que dificulta enormemente su posibilidad de incorporación como recurso turístico y económico para la región.

Para la comprensión del problema se aborda un espacio físico de características particulares -importantes pendientes, relieve escarpado, vegetación achaparrada- en un tiempo histórico que revela la transición entre el final de siglo XIX y el comienzo del siglo XX, período conocido como la modernidad. A partir de un estudio de casos se revela la coexistencia de inversiones de gestión pública y privada. Puntualmente centramos el estudio en el valle de Cacheuta, donde vislumbramos que los efectos de la modernidad provocaron, además de la incorporación de nuevas tecnologías y materialidades a los procesos productivos, nuevas formas de interacción social en relación con el ocio y sentaron las bases para el poblamiento histórico de la zona. El ferrocarril y la trama vial constituyen el hilo conductor que guió estas intervenciones pioneras.

Palabras clave: modernidad, enclave Cacheuta, infraestructura y arquitectura, Mendoza

\section{ABSTRACT}

This investigation focuses on the detection of a vacancy of an integral approaching of the cultural goods on the middle section of the Mendoza River, in the central portion of the Argentinian Andes. Nowadays it has been advanced only in a limited look in the study of historical goods that consolidated the territory, which impedes enormously the possibility of reincorporation of such goods as tourist and economic resource for the region.

For the comprehension of the problem it has been proposed an approach to physical space of particular characteristics - sharp slopes, steep morphology of the soil surfaces, stocky vegetation - in a historical time that reveals the transition between the end of 19th century and the beginning of the 20th century, period known as the "modernity". Starting from the methodology of case study we intended to reveal the coexistence of intentions and investments of public and private management. Particularly, in the area known as "Cacheuta valley", where some of the effects of this modernity show the introduction of new technologies in productive processes, new ways of social interaction and established the foundations for the permanent historical settlement of this area. The railroad and the road plot constitute the guiding thread that leaded these pioneering interventions.

Keywords: modernity, Cacheuta settlement, infrastructure and architecture, Mendoza 


\section{INTRODUCCIÓN}

A lo largo de cuatro siglos de historia se establecieron en los tramos superior y medio del Río Mendoza, asentamientos productivos relacionados con la industria minera, la industria agropecuaria, la industria turística, hidroeléctrica y vitivinícola. Interesa abordar aquí el tramo cordillerano intermedio y el desarrollo suscitado en el valle de Cacheuta, en el departamento de Luján de Cuyo, eslabón articulador de una cadena de asentamientos que conforman el Corredor Bioceánico con el paso Cristo Redentor, hacia la vecina República de Chile. El valle de Cacheuta es un espacio aglutinante de infraestructuras edilicias y servicios que lo convierten en un nodo de caracteres particulares donde se suman testimonios finiseculares que atestiguan manifestaciones del ingreso a la modernidad en la provincia de Mendoza.

Se trata de un valle longitudinal paralelo al cauce del río Mendoza, ubicado a $40 \mathrm{~km}$ hacia el oeste de la ciudad homónima, con una altitud aproximada de 1.200 metros sobre el nivel del mar. Se caracteriza por pendientes abruptas y vegetación variada, donde se observan no sólo la presencia de especies autóctonas sino también la introducción de especias exóticas que han transformado notablemente el medio, en un paisaje natural y cultural $^{1}$ de características propias.

1 Tedeschi, Enrico (1972) Teoría de la Arquitectura.
En el devenir histórico cordillerano el advenimiento del ferrocarril, los caminos, las infraestructuras de generación hidroeléctrica, las infraestructuras turísticas que se desarrollaron a la luz de la idea del progreso industrial y los principios higienistas, generaron huellas materiales e intangibles que constituyen, en su conjunto, un paisaje cultural singular referido a la producción. Para el desarrollo de este trabajo se aborda un espacio físico- geográfico de características únicas en un tiempo histórico que revela la transición entre el final de siglo XIX y el comienzo del siglo $X X$, período conocido como la modernidad, con emprendimientos que, llegados hasta nuestros días, han sufrido un proceso de metamorfosis significativo. En este contexto, el enclave ${ }^{2}$ Cacheuta adquiere, por su posición estratégica y morfología, protagonismo como articulador del paisaje de montaña y sede de actuaciones productivas sobre el territorio que implicaron la aportación de saberes y técnicas nacionales y extranjeras.

A partir del estudio de caso del enclave Cacheuta, comprendido temporalmente entre los años 1890 -bajo la gestión de los gobiernos liberales conservadores- y 1930 -con los primeros gobiernos democráticos- se revela la

2 En esta investigación, se entiende por enclave a una porción acotada del territorio, con características particulares en lo político, administrativo, geográfico, etc. que le otorgan identidad respecto de otros territorios. 


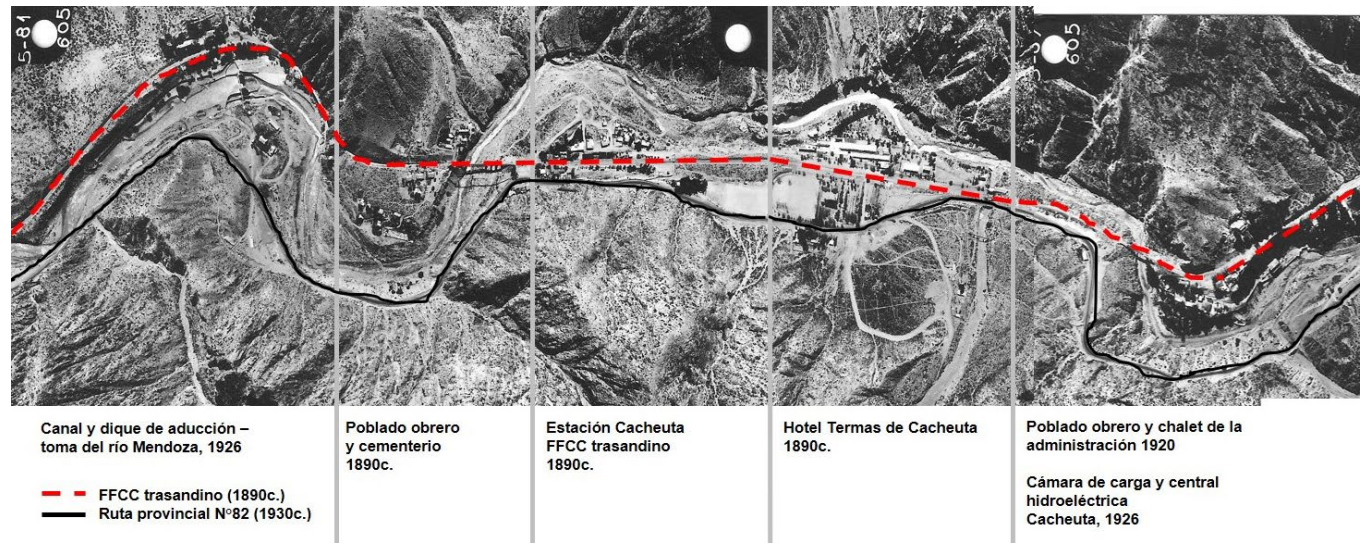

Figura 1

Mosaico fotogramétrico que muestra el enclave Cacheuta y sus componentes más destacados (elaboración de los autores a partir de imágenes de archivo del Ente Provincial Regulador Eléctrico-EPRE, 1950c.)

coexistencia de inversiones de gestión pública y privada para la consolidación del territorio, a través de evidencias físicas como la traza del ferrocarril, los caminos, la aparición de asentamientos cordilleranos e intervenciones productivas en el lecho del río, acontecimientos ocurridos en el contexto moderno ya enunciado. El trabajo que aquí se presenta se desprende de una investigación de mayor envergadura, que consistió en estudiar pormenorizadamente el sistema productivo agroindustrial y energético del sistema hídrico del río Mendoza, junto a sus canales Zanjón y San Martin en la provincia de Mendoza, en el oeste de Argentina. Dicha investigación fue desarrollada en el marco de la segunda convocatoria para iniciar proyectos financiados por la Universidad de Mendoza, dentro del ICAU -Instituto de Cultura Arquitectónica y Urbana- entre los años 2013 y 2015. Se vincula también a un proyecto actualmente en ejecución, desarrollado en el marco de la primer convocatoria de la DIUM- Departamento de Investigaciones de la Universidad de Mendoza- entre los años 2017 y 2019.

\section{HIPOTESIS, OBJETIVOS Y METODOLOGIA. ESTADO DEL ARTE}

Se parte del supuesto que el ingreso de Mendoza a la modernidad, en un contexto de montaña, se sustentó en la generación de la energía hidroeléctrica y el desarrollo del turismo, acciones posibles gracias a la implantación pionera del ferrocarril a fines del siglo XIX. La ocupación precursora del tramo medio del río Mendoza, donde se ubica este caso de estudio, fue viable por el tendido de la línea férrea, lo que significó mayor fluidez de las comunicaciones entre la ciudad y el valle, a 
la vez que permitió el transporte de personas, materiales y mercancías.

A su vez, las infraestructuras de acompañamiento, como caminos, líneas telegráficas, puentes, acueductos y estaciones de ferrocarril, entre otras, constituyeron un paisaje cultural propio de ese momento histórico. Esto permitió el asentamiento de grupos humanos en distintos puntos del valle, que se desarrollaron y consolidaron en el período bajo estudio, constituyéndose en ejemplos destacadísimos de acciones de poblamiento en tiempos históricos, que revelaron en sus materialidades, en las tecnologías y en las prácticas sociales adoptadas, un ingreso decisivo en la modernidad de fin de siglo. Se observa que estas acciones, leídas en conjunto, presentan un caso paradigmático en el análisis del enclave Cacheuta, que, como caso de estudio, reúne una -o varias- manifestaciones materiales de cada uno de los adelantos enunciados.

La conceptualización de modernidad a la que adhiere esta investigación está vinculada a los orígenes del capitalismo, donde la tecnología es un elemento importante marcado en la Ilustración, junto a una mención de conceptos como Modernización y Modernismo que son característicos del siglo XX. Retomando a Marshall Berman, se considera que "el pensamiento sobre la modernidad está dividido en dos compartimientos diferentes, herméticamente cerrados y separados entre sí: la modernización en economía y política; el modernismo, en el arte, la cultura y la sensibilidad". En otras palabras, la visión de la vida moderna tiende a dividirse entre el plano material y el espiritual:

algunos se dedican al modernismo, que ven como una especie de espíritu puro que evoluciona de acuerdo con sus imperativos artísticos e intelectuales autónomos; otros operan dentro de la órbita de la modernización, un complejo de estructuras y procesos materiales -políticos, económicos y sociales [...] (Berman, 1982: 82).

Se proponen como objetivos de esta investigación:

- Construir un aporte en un área de vacancia temática referida a un estudio sistémico que aborde la lectura del territorio en sus dimensiones técnica, arquitectónica, urbanística y de la práctica turística.

- Indagar, a partir del estudio de caso, en los rasgos característicos de la dimensión material de los edificios e infraestructuras estudiados.

Para el abordaje del caso seleccionado, se recurrió a una metodología cualitativa. Tomando a Sautu (2005), se encuadra la investigación desde lo macrosocial, que "tiene como propósito indagar en la estructura social, de las instituciones, las sociedades y sus culturas, incluyendo cuestiones vinculadas a los procesos históricos" (Sautu, 2005: 52). Este 
trabajo adhiere al modelo narrativo histórico, que entiende el estudio de las sociedades, sus culturas y el cambio histórico a partir del análisis de datos secundarios agregados y fuentes documentales, lo que permite mirar a la sociedad y la economía entre sí como fenómenos vinculados en un contexto históricopolítico (Sautu, 2005).

El abordaje histórico se realiza a la luz de la propuesta teórica de Waisman, dentro de la temática de la historia de la arquitectura en el contexto latinoamericano y la construcción de la identidad (Waisman, 1993). La autora refiere a la lectura del edificio como documento histórico (Waisman, 1972), en tanto y en cuanto su materialidad, tipología, tecnologías empleadas y los personajes intervinientes en su construcción remiten a las fuerzas productivas y la cultura de la época, que se transmiten a través de la obra.

Mientras que, para examinar los paisajes históricos de la producción, se toma el concepto de diagnósticos de área propuestos por el antropólogo Julián Sobrino Simal en su trabajo "Los paisajes históricos de la producción en Cuba" (2015). El autor sostiene que, con esta estrategia de análisis, se apunta a definir espacios de marcada identidad. Define variables e indicadores para la detección de capacidades y atributos del paisaje en un enfoque teórico-metodológico que intenta aportar una nueva e integral visión de los escenarios de la producción. Para ello, propone como variables de análisis la lógica territorial, recursos primarios, potencial articulador $y$ generador de infraestructuras, técnicas $y$ tecnologías aplicadas (FFCC, rutas, vialidades y construcciones), y espacio de la producción existente (infraestructuras del agua, generación y / o transporte de energía).

Respecto de los avances efectuados en esta línea, Larrinaga Rodríguez (uno de los más importantes especialistas en historia del turismo) estudia el desarrollo de las infraestructuras camineras y ferroviarias junto al posicionamiento de San Sebastián como sitio turístico paradigmático de la península ibérica (2007 y 2005). El aporte de Gómez Días Franzón (2011) en "Arquitectura del veraneo y su época en Sanlúcar de Barrameda 19001950" destaca fundamentalmente la idea del turismo vinculado con la modernización, donde describe con detalle cómo el veraneo transformó el urbanismo, las infraestructuras y la arquitectura del pueblo gaditano.

Por su parte, Ponte establece un antecedente relevante en el abordaje desde la historia y el ingreso de Mendoza a la modernidad, al plantear en su libro "La fragilidad de la memoria" (1999) las representaciones generadas por los grupos dominantes, puestas en tensión con las representaciones del resto de la población, en la construcción de una ciudad moderna, junto a la materialización de aquellas representaciones en el espacio público, en el período 1885-1910. Su aporte se sostiene en el análisis de periódicos 


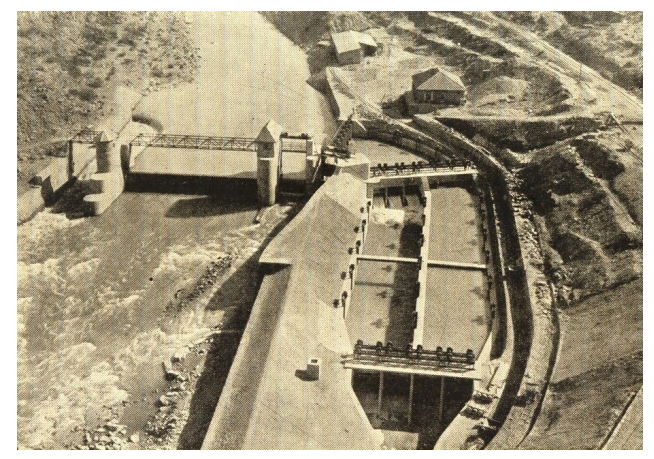

Figura 2

Represa en la toma del río Mendoza, con el dique cerrado (Empresa Luz y Fuerza, 1926)

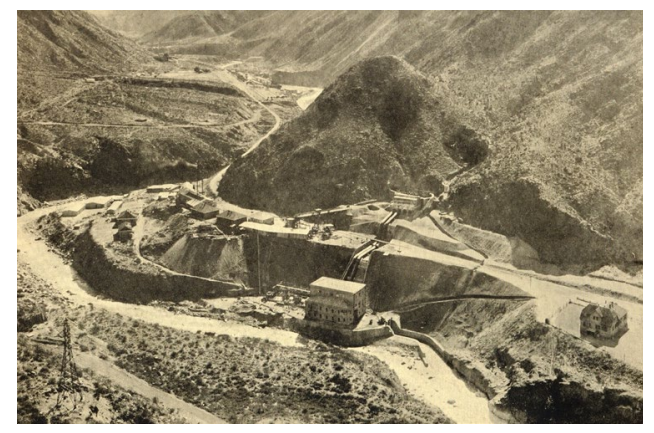

Figura 3

Vista gneral de la central hidroeléctrica Cacheuta (Empresa Luz y Fuerza, 1926)

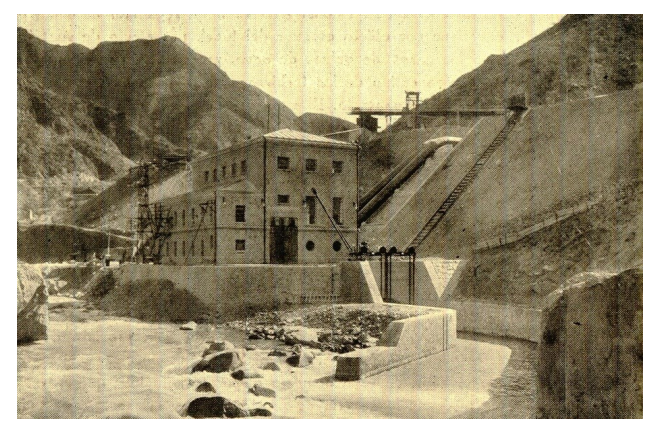

Figura 4

Vista de la sala de máquinas o usina (Empresa Luz y Fuerza, 1926) y otras fuentes escritas de la época. Refuerza esta visión de modernidad la investigación de Ana María Mateu, quien retoma la visión tecnológica del fenómeno al considerar los avances producidos por el tranvía y el uso de la energía eléctrica en la ciudad, en la compilación "Mendoza a través de su historia" (2004).

Otros estudios en materia de historia del turismo e infraestructuras de alta montaña han sido incluidos en el trabajo de Lacoste (2013, 2004 y 1998). En este sentido, es de destacar su historización del fenómeno turístico desde una escala que vincula las acciones de una empresa privada y las prácticas pioneras del turismo de alta montaña, como también la importancia del Ferrocarril Trasandino Central (FTC) en el proceso de integración entre Argentina y Chile.

\section{DESARROLLO CODIGO DEÁREA}

Esta investigación, que aplica como metodología la descripción e interpretación de campo sumada a la búsqueda bibliográfica y archivística, ha posibilitado definir y caracterizar el tramo geográfico del enclave Cacheuta, como ejemplo destacado dentro del valle homónimo. Este proceso permite construir sistémicamente en toda su complejidad el paisaje histórico de la producción en un escenario de montaña, y revelar los hechos que testimonian la modernidad. El abordaje incluye la descripción de su lógica territorial y la inserción de los recursos primarios base de la producción, implantación y relaciones de contexto. 


\section{Lógica territorial}

El enclave Cacheuta se ubica en un sector montañoso de la precordillera de los Andes, con alturas intermedias de 1.150 y 1.430 m. s. n. $\mathrm{m}$. entre las localidades del dique Potrerillos y el dique Cipolletti. Este tramo escarpado refiere al lecho natural del río Mendoza, que discurre en sentido sureste desde el dique Potrerillos en una quebrada entre montañas con un cauce estrecho y abrupto. El lecho del río, de marcada pendiente, es peñascoso y las paredes que lo definen forman una unidad morfológica única. Presenta una marcada variabilidad térmica, con vientos frescos y régimen de precipitaciones estivales. Su flora es xerófila, manifiesta en vegetación achaparrada, de gruesos troncos adaptadas al calor y al medio seco (jarillas, chañares, cactáceas, espinillos, etc.). El suelo es rico en minerales, ripios y piedras, y metales no metalíferos (sílice, azufre, barita, caolín, celestita, diatomita, dolomita, fluorita, feldespato, fosforita, fluorita, grafito, sal, sulfato de sodio, sulfato de magnesio, wollastonita y yeso), que convierten a Cacheuta en un distrito minero por excelencia (Inchauspe y Marzo, 1967).

El sector se define con un paisaje característico de montaña. Posee un macizo plano o morro serpenteante y paralelo al río que, recostado sobre el cerro Cacheuta al oeste, da lugar a la instalación de emprendimientos productivos. Su morfología permite el asentamiento disgregado de barrios de obreros y técnicos, asociados al trabajo del aprovechamiento hídrico en la

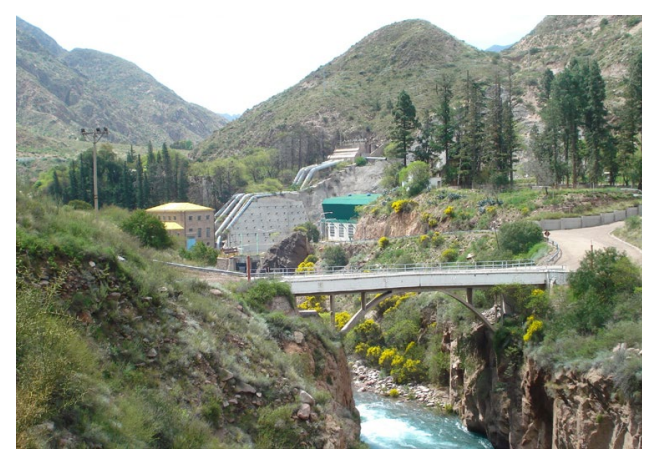

Figura 5

Vista actual de la central antigua (izq.) y nueva (der.) (Pablo Bianchi, 2015)

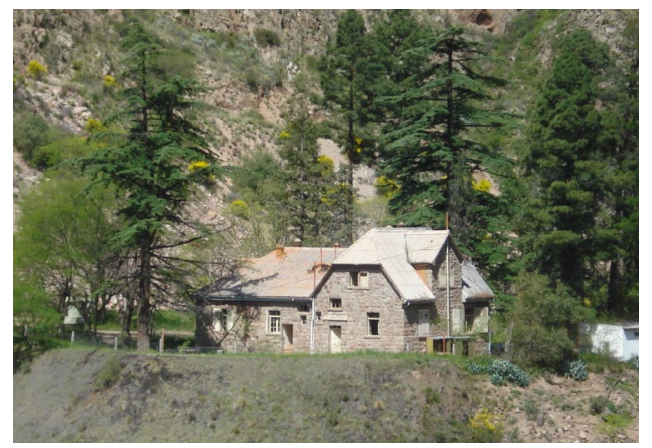

Figura 6

Vista actual del chalet de la administración, central hidroeléctrica Cacheuta (Pablo Bianchi, 2015) 
Central Hidroeléctrica Cacheuta I (1913) y al Hotel Termal Cacheuta (1890 c.) que aprovecha vertientes naturales de aguas calientes, sulfurosas y de propiedad terapéutica.

\section{Recursos Primarios}

En el enclave Cacheuta los recursos primarios se centran en la explotación de las propiedades medicinales de sus aguas y el recurso hídrico. El primero es el que marca la presencia en el sitio desde tiempos precolombinos, donde se acudía en busca de terapias curativas a partir de las afloraciones termales (Acordinaro, 2009), actividad que se arraiga con el tiempo y permite un proceso de crecimiento de infraestructuras desde la aparición de alberges de carácter doméstico, como la posada Quirós ${ }^{3}$ (1890 c.), hasta culminar en el desarrollo turístico y la implantación del Hotel Termal Cacheuta, por la Compañía de Hoteles Sud Americanos Ltda., una empresa subsidiaria del ferrocarril encargada de su explotación y difusión turística (Lacoste, 1998). El segundo recurso se centra en la generación de energía limpia en cuanto a su producción y transporte. La energía

3 Las publicidades relevadas en la Revista Mensual BAP y la revista Luz y Fuerza, junto con la observación directa de este emprendimiento (que, con otro nombre, pero en el mismo sitio se desarrolla hasta la actualidad), permiten confirmar que las primeras edificaciones de este conjunto responden al tiempo histórico de implantación del ferrocarril, junto a un cementerio de la misma época que se despliega en una de las laderas del cerro. fue producida en el enclave por la central hidroeléctrica Cacheuta I sobre el curso del río y actualmente por la central Cacheuta II (2002), de embalse. Actualmente ambas constituyen un activo económico estructural de importancia para la pervivencia y desarrollo del sector.

El dique Potrerillos se ubica próximo, a 1.435 m. s. n. m., y tiene la propiedad de ser un embalse regulador y administrador de agua para riego, no obstante, el agua de riego carece del ordenamiento en canales, acequias e hijuelas en la zona de estudio. El agua de consumo humano se cubre por el suministro de la planta potabilizadora de la empresa Agua y Saneamiento Mendoza (en adelante AYSAM), de 1930, frente al río Blanco. Existen algunos canales naturales secos, convertidos en calles de piedra que en momentos de lluvia se convierten en colectores aluvionales desembocando directamente en la cuenca del río Mendoza.

La explotación de la industria turística constituye un activo económico de importancia en el sector. Posee infraestructura para el desarrollo de deportes de montaña, hosterías y presencia de emprendimientos privados como Las Aguas de Pizarro (con su origen en el asiento en la zona de antiguos puestos ganaderos) y concesiones de explotación desde el Estado para otras vertientes naturales cercanas al hotel de Cacheuta. Otro bien que forma parte de un patrimonio natural, paisajístico y ambiental, que debe ser leído en clave sistémica, lo 
constituye el yacimiento paleontológico Agua de las Avispas en el cerro Cacheuta, declarado de interés por disposición provincial $N^{\circ} 005 / 2000$. Los bienes del patrimonio cultural nacional y del patrimonio cultural provincial ubicados en la ruta provincial $N^{\circ} 82$, ligados a la historia cultural y desarrollo del oasis productivo, que actualmente se encuentran en desuso, incluyen la Central Hidroeléctrica de Cacheuta I (decreto N 916/2004), la Usina de Fader, de 1906 y los puentes del ferrocarril de Cacheuta (1885), protegidos bajo el decreto $N^{\circ} 1059 / 2002$. El Puente Colgante (de 1953, habilitado actualmente y de acceso peatonal), se encuentra bajo el amparo de la reglamentación nacional $N^{\circ} 1063$.

\section{Potencial articulador y generador de infraestructura}

El sector presenta amplio desarrollo de infraestructura vial, la ruta provincial $N^{\circ} 82$ (1930) estructura el territorio en el tramo observado. Su traza une puntos de interés de distinta naturaleza y envergadura, patrimonios edificados referidos a infraestructuras hoteleras, ferrocarrileras, energéticas y de riego. La infraestructura del FTC (1890), implantada por empresas inglesas, se desarrolla paralela a la ruta y no opera en la actualidad. Constituye un testimonio de las mayores obras de ingeniería de Mendoza, el país y América del Sur (Lacoste, 1998: 85). Implica notables montajes, apertura de la traza, construcción de puentes, instalación de durmientes y rieles y sobre todo la perforación realizada con

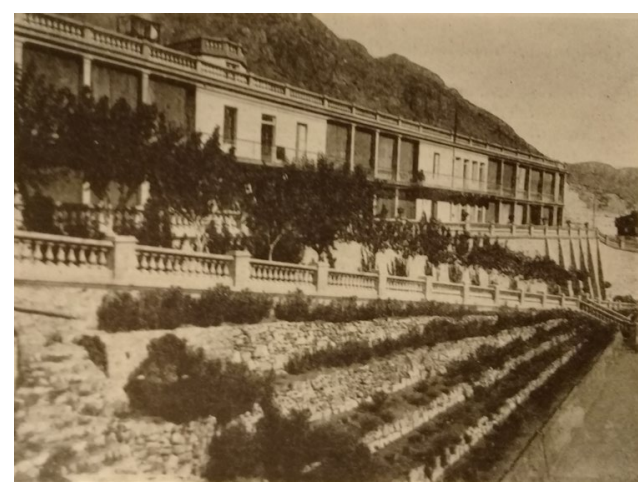

Figura 7

Vista norte del hotel y acceso a las termas (Libro de Oro de Cacheuta, 1930)

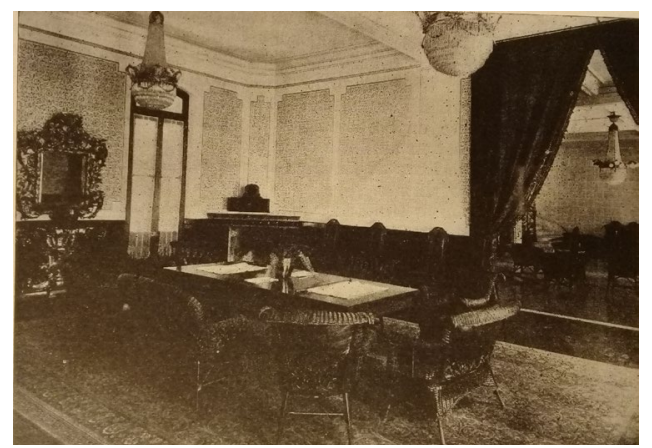

Figura 8

Sala de lectura (Libro de Oro de Cacheuta, 1930)

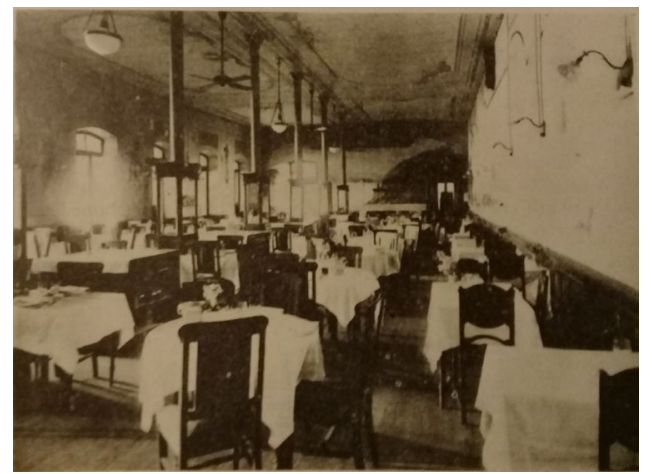

Figura 9

Comedor interno del hotel (Libro de Oro de Cacheuta, 1930) 


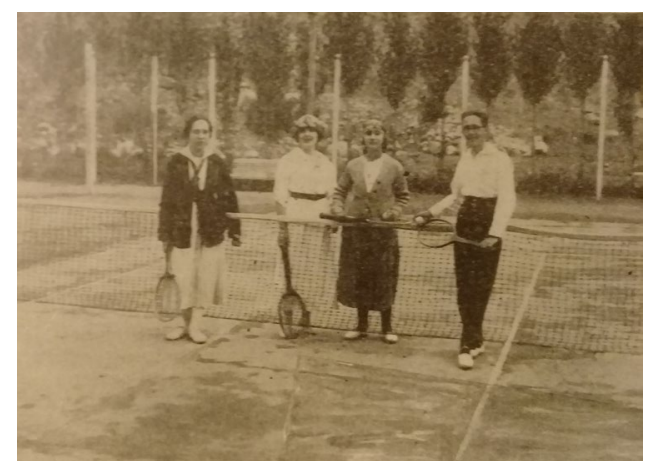

Figura 10

Cancha de tenis (Libro de Oro de Cacheuta, 1930)

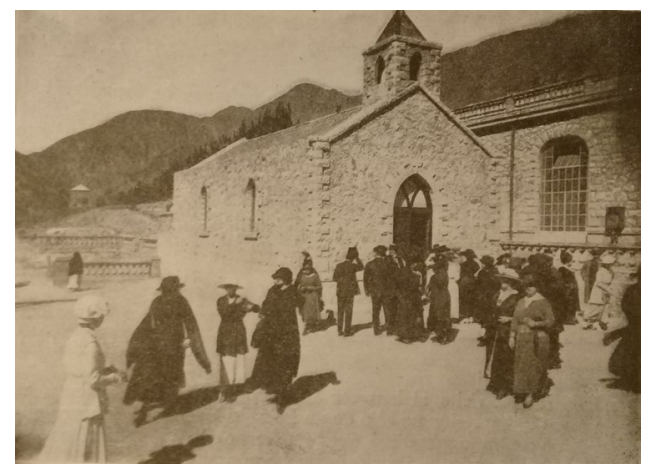

Figura 11

Una salida de misa (Libro de Oro de Cacheuta, 1930) dinamita recién descubierta (1880c.) del túnel de La Cumbre (1910) a una altura de 3.000 m. s. n. m. y un desarrollo de 3 km (Lacoste, 2013). El ferrocarril fue sin duda el impulsor del desarrollo en la montaña, seguido por la construcción de caminos de acompañamiento, como la ruta provincial mencionada.

\section{Técnicas y tecnologías aplicadas}

El enclave Cacheuta presenta un patrimonio edificado no homogéneo, de gran variabilidad debido a la materialidad y escala como a la envergadura de las tipologías que representa. Es contenedor de notables arquitecturas, obras de ingeniería e infraestructuras. Las arquitecturas para el ocio y recreación, como el edificio hotelero de Cacheuta, presentaban tecnologías tradicionales de ladrillo y hormigón, o bien evidenciaban la incorporación del cemento armado y el uso de vigas reticuladas en acero; y abrazaban un lenguaje neoclásico o pintoresco con la presencia de la piedra como material predominante. Los complejos hidroeléctricos, por su parte, expresados en lenguajes de racionalidad y abstracción, u obras de ingeniería industrial del siglo pasado (con materiales del lugar y técnicas tradicionales) simbolizan el avance tecnológico de su tiempo. Las obras del ferrocarril y sus instalaciones en hierro, piedra, hormigón y chapa; puentes de hierro y piedra, túneles de hormigón o socavados en la roca, presentan lenguajes tecnológicos y utilitarios. Las formas de construir, los montajes, soldaduras, abulonamientos, usos de laminados, prefabricados, empotramientos, 
etc., dan testimonio de la revolución tecnológica en la provincia, consecuencia de la Primera y Segunda Revolución Industrial que pregnó al mundo. Son hechos que testimonian la presencia y saberes de ingenieros y cuerpos técnicos ocupados en la dirección técnica de las obras de infraestructura y del sistema de montaje de los equipamientos.

\section{Espacios construidos para la producción}

Los bienes de la producción energética detectados son de envergadura en cuanto a inversión y capacidad productiva. Es necesario hacer notar que, en el diagnóstico del sector, se concentran patrimonios industriales edificados en estado ruinoso como la Usina de Fader ${ }^{4}$, a escasos kilómetros de la central Cacheuta I (de abandono reciente con un destino incierto) y como contrapartida presenta la dualidad de un patrimonio energético nuevo (Cacheuta II) construida e inaugurada recientemente, contigua a la primera. Por su escala y envergadura, y al constituir testimonios únicos

$4 \quad$ La obra hidroeléctrica iniciada por Carlos Fader ocupa el tercer lugar en el proceso cronológico del país, detrás de las de San Roque en Córdoba y Lules en Tucumán. En 1906, la Cámara de Diputados de la Provincia de Mendoza, prorroga por cuatro años el plazo fijado a Carlos Fader para ejecutar obras en cumplimiento de la concesión que se le había acordado por ley № 117/1899. Hacia 1910 la obra estaba prácticamente finalizada pero en febrero de 1913 un aluvión cordillerano destruye las instalaciones y la deja inoperante (Gutiérrez Viñuales, 1998). de la modernidad en el sector estudiado, se ha abordado el hotel Termas de Cacheuta en primer término y luego la central homónima.

Hacia 1893 se construye un hotel modesto en el sitio y las primeras piletas balnearias a la vera del río, aprovechando vertientes naturales de aguas termales ${ }^{5}$. Hacia 1913 las antiguas instalaciones son remodeladas y ampliadas, siendo la única posibilidad de acceder a través del ferrocarril. El nuevo edificio, inspirado en las villas de recreo del norte de Italia, se presentaba como un conjunto de dos volúmenes alineados de base rectangular, paralelos al discurrir del río Mendoza. La volumetría compacta, de cubiertas planas, marcaba una sucesión ritmada de llenos y vacíos (balcones soportados por columnas), que alternaban con tres ventanas en los paños llenos, repitiendo el esquema de manera que conformaba una extensa fachada hacia el río, de casi $180 \mathrm{~m}$ de longitud. El remate estaba constituido por una línea de balaustres que coronaba el perímetro de los edificios, al mismo tiempo que delineaba las circulaciones y las terrazas con vistas al río y a los cerros.
$5 \quad$ El Libro de Oro de Cacheuta da cuenta del carácter que tenían estas primeras instalaciones, desarrolladas con una materialidad muy precaria, pero de notable envergadura para la época: incluía las habitaciones de baño con piletas termales en una de las márgenes del río junto con un gran edificio, en la ladera del cerro, destinado a recepción, restaurant y habitaciones para el alojamiento de huéspedes. 
Entre sus comodidades presentaba dos ascensores: uno al oeste, que comunicaba con la estación del ferrocarril y otra al este, que descendía vinculando el nivel de la rambla de paseo del hotel con la galería de baños termales ubicada a la vera del río, a las que se accedía por un pasillo alargado, de 70 m de longitud, con un lucernario central de cristal y hierro. El hotel poseía además salas de billar y salas de estar. Llegó a contar con 150 habitaciones, capilla, lavadero para la ropa de huéspedes, cocina, pastelería, panadería, dos restaurantes (uno para mayores y otro para niños), consultorio médico, farmacia, peluquería, casino, cine, salón de baile y salón de lectura (Revista Mensual BAP, 1922), pabellón de beneficencia, edificio de administración, viviendas para los empleados y corrales para animales de granja.

Por su parte, el complejo hidroeléctrico estaba constituido por una represa de embalse (a la altura del km 40 del FTC), que tomaba agua del río Mendoza. Luego el vertedero de $38 \mathrm{~m}$ de largo, en la margen derecha del río, para evacuar el exceso de aguas en caso de crecidas repentinas. Luego la toma compuesta por ocho compuertas de hierro de $3 \mathrm{~m}$ de ancho por $2 \mathrm{~m}$ de alto cada una, con una pasarela de maniobras. El agua pasaba de allí hacia cámaras de decantación, para minimizar la tierra en suspensión que pudiese contener, y a un túnel de 3,72 $\mathrm{m}$ de alto y 3,64 m de ancho, excavado completamente en la roca, con sección de herradura, con una longitud de 2.366,70 m, que conducía las aguas hacia la cámara de carga, a cielo abierto, construida en hormigón armado. A su lado se ubicaban filtros potabilizadores para provisión de agua potable al personal de la usina (Empresa Luz y Fuerza, 1926).

De allí el agua era enviada por la tubería de presión, constituida por cuatro caños de acero entre $1600 \mathrm{~mm}$ a $1800 \mathrm{~mm}$ de diámetro, al edificio principal que contenía dos grupos turbogeneradores, de eje vertical, de 3.300 KW cada uno, acoplados a los generadores eléctricos, regulador de turbina, tableros de comando y tableros eléctricos (Empresa Luz y Fuerza, 1926). La tensión generada en la central era conducida a la ciudad de Mendoza por medio de una línea de transmisión.

\section{Relaciones de Contexto}

El enclave Cacheuta es poseedor de afortunadas coincidencias que lo posicionan irremediablemente en el marco de los intereses de la economía mundial. Su estratégica posición geopolítica de lugar limítrofe y equidistante de otros países latinoamericanos lo llevó a ubicarse, desde fines del siglo XIX (a partir de la implantación de la traza del FTC), como protagonista de la ruta que enlazaba Buenos Aires con Santiago de Chile. El ferrocarril contribuyó a la transformación de la montaña en un espacio social, especialmente apto para el turismo. Debió "enfrentar una tradición cultural que había condenado a la cordillera a la marginación, manteniéndola como lugar desierto" (Lacoste, 2013: 223). Pero con su 
aporte "al mejoramiento de la infraestructura, el equipamiento, las instalaciones y la superestructura turística, se consagró una actitud para la incorporación de este amplio territorio a la actividad socioeconómica de la región" (ídem).

En este sentido, la tarea de promoción jugó un papel fundamental, dado que era necesario hacer conocer los servicios que prestaba el hotel, fundamentalmente en Buenos Aires y Santiago. Así, surgieron importantes campañas de publicidad gráfica en los diarios más importantes de la época, como también mediante las publicaciones propias de las empresas ferrocarrileras, como la Revista Mensual BAP (Lacoste, 2013).

Avanzado el siglo XX, se constituyó en un eslabón del Corredor Bioceánico, como punto de conexión entre Puerto Alegre en Brasil con Coquimbo en Chile, formando parte de un instrumento físico-territorial que agilizó el intercambio comercial de los países del cono sur, a la vez que facilitó la integración cultural de las naciones. Sumado a ello, y en un contexto beneficioso que le propicia el tratado del Mercosur (1994) el sector se desarrolló logísticamente en la búsqueda de una apertura a los mercados del Pacífico.

\section{RESULTADOS}

El trabajo de investigación aporta resultados parciales que se desprenden del grado de avance logrado a la fecha. Los resultados validan la hipótesis que expone la comprobación de los hechos y signos que testimonian el arribo de la modernidad al tramo intermedio del río Mendoza, concretamente en el enclave Cacheuta.

En primer lugar, se confirma, por medio de una serie de infraestructuras y de la implantación de arquitecturas, la construcción de un sistema eficiente y progresista que jalonó el territorio y permitió el asentamiento permanente y creciente de grupos humanos en todo el período estudiado. A ellas responden tanto la traza del FTC, junto con sus estaciones intermedias, como la ruta provincial $N^{\circ} 82$. Respecto de las arquitecturas destacadas, resalta la construcción del hotel Termas de Cacheuta, junto al poblado que surgió en torno de la estación del ferrocarril. Para ello, fue necesaria la instalación de infraestructuras de potabilización del agua, para hacerla apta para el consumo humano.

Por otra parte, junto a la central hidroeléctrica también se estableció un asentamiento humano permanente, inicialmente el barrio obrero que demandaba la construcción de la central en un contexto de montaña. En un segundo momento 
se detectan, en planos históricos ${ }^{6}$, grupos de viviendas de familias instaladas en el sector, relacionadas con los primeros asentamientos obreros. Por su parte, el funcionamiento de la central demandaba, además, operarios de forma permanente, para lo cual se construyeron viviendas para los empleados y un chalet de administración para el personal jerárquico.

Respecto de los adelantos técnicos y tecnológicos manifestados en las infraestructuras resueltas con saberes y dirección de empresarios y técnicos extranjeros, se relevaron, a lo largo del tendido ferroviario, montajes de rieles, excavaciones de túneles por voladura de cerros y ejecución de puentes en piedra con arquerías. La traza viaria, por su parte, evidencia conocimientos técnicos más avanzados, propios de su momento histórico, para la ejecución de la ruta destinada al automóvil: técnicas de pavimentos de hormigón o asfalto para caminos.

Respecto del hotel termal, se observa una mecanización de su equipamiento (ascensores y equipos importados), una innovación tecnológica en el uso del acero en vigas reticuladas, para la resolución de cubiertas de áreas comunes (estares, restaurant, salas de lectura), como también instalación de modernas tecnologías en diversos servicios del hotel: conservación de alimentos (cámaras

6 Los mismos fueron relevados en el archivo documental del EPRE - Ente Provincial Regulador Eléctrico. frigoríficas), equipamiento para proyección cinematográfica, lavadero, sistema central de calefacción, sistema de bombeo para el agua, empleo de estructuras innovadoras en acero y cristal para la cubierta de la galería de baños, entre otros adelantos.

Por su parte, en la central hidroeléctrica, destaca el tendido de infraestructura con altas tecnologías en hormigón armado, hierro y acero, construcción de canales de aducción y restitución, cámaras, azudes, puentes, perforaciones, construcciones de túneles para conductos. Como también el tendido telegráfico para comunicar con la sede central de la prestataria del servicio eléctrico en la ciudad de Mendoza. Se registró el uso de tecnología importada en equipos de precisión, uso de equipos importados de producción de Francia, Alemania y Bélgica, sumado a la práctica de saberes extranjeros (ensambles y montajes). Posteriormente se incorporó una línea telefónica para el control de la línea de alta tensión. En el campo edilicio cabe citar el empleo de técnicas constructivas con tecnología de punta en prefabricados, usados para los barrios obreros, o la implementación de infraestructuras de comunicaciones y de distribución de aguas potables y servidas.

Finalmente, el estudio de las actividades referidas al ocio y turismo en la montaña permite confirmar una nueva forma de socialización, a partir de construir un escenario turístico surgido de las prácticas de descanso y recreación. 
Las publicidades, notas gráficas y fotografías relevadas tanto en la Revista Mensual BAP, como en El Libro de Oro de Cacheuta dan cuenta de una agitada vida social. La primera de las fuentes resalta los espacios al aire libre y las actividades ofrecidas por el hotel, como las ramblas para caminatas (designación que emulaba al aristocrático paseo marplatense de fines de siglo XIX), canchas de tenis, piscina descubierta, juegos para niños, miradores y jardines, en el contexto imponente del valle cordillerano. En tanto que las notas gráficas de El libro de Oro destacan, entre los atractivos del hotel, las salas de lectura, un cine-teatro, sala de billar, casino, salón de baile y capilla para los servicios religiosos de los domingos. Las publicaciones hacen alarde de la calidad del servicio y de una distinguida concurrencia ${ }^{7}$, calificando al hotel como "el Titanic de los Andes", el hotel con el que "la industria hotelera hace honor al país", o "la perla de los Andes" (Revista Mensual BAP, 1922).

$7 \quad$ Entre sus visitantes ilustres, la publicación consultada destaca la presencia del Sr. Ezequiel Ramos Mexía, Dr. Enrique García Merou, Sr. John Nelson, Ing. Otto Grieben, el expresidente Dr. Victorino de la Plaza, Dr. Manuel B. Gonnet, Sra. Teodelina Alvear de Lezica, Sra. Hersilia Lynch de Casares, Dr. Benjamín Williams, Dr. Carlos Heuser, Sr. Pedro Christophersen, Sr. Enrique de Anchorena, Sr. Mariano Díaz de Mendoza, Sir James Sutherland, Dr. Federico de Alvear, Dr. Hugo Cullen, el nuncio apostólico Mons. Felipe Cortesi y el obispo de Mendoza Mons. José A. Orzali.

\section{CONCLUSIONES}

El desarrollo de la presente investigación permitió dilucidar el modo en que un enclave de montaña evidenció en sus signos materiales la presencia de la modernidad, revelando un conjunto de bienes significativos que marcaron hitos en el devenir histórico del poblamiento de la zona, entre finales del siglo XIX y principios del siglo XX. La relación que existe entre los emprendimientos autóctonos seleccionados para analizar el caso bajo estudio, de alto valor histórico y testimonial, tiene su raíz común tanto en el paisaje indómito de la cordillera, en un tiempo de trabajo humano pionero, como en un auténtico momento de quiebre para Mendoza: la revolución tecnológica finisecular, consecuencia de la Primera y Segunda Revolución Industrial.

La visión cultural empleada contribuye a tomar real dimensión de las aristas que desplegó la modernidad en el valle de Cacheuta. Se detectó una nueva visión de mundo, que se tradujo en el empleo de nuevas tecnologías, confianza absoluta en la técnica, incorporación de nuevos saberes y nuevas prácticas sociales, lo que permitió el acrecentamiento del espacio social sobre un territorio que en otro momento histórico fue indómito.

El turismo como práctica de la elite fue incorporado al valle de la mano de los ingleses, propietarios del Ferrocarril BAP, quienes no hicieron más que trasladar a los Andes centrales 
de Argentina la experiencia que se estaba realizando en Europa (Lacoste, 2013). En este sentido, "Ios baños termales constituían un elemento convocante para la actividad turística, pero como punto de partida para una propuesta mucho más rica" (Lacoste, 2013: 243): era la base sobre la cual construir un conjunto de actividades recreativas, culturales y de intercambio, en un marco de confort, elegancia y distinción.

La investigación desarrollada permitió identificar una serie de acciones que ayudan a comprender e interpretar el territorio, facilitan una lectura de las materialidades e intangibles que lo componen, al tiempo que permiten descubrir los elementos que lo estructuran y lo relacionan sistémicamente. La lectura integradora de hechos y realizaciones refuerza la noción de unidad territorial de cada uno de los ejemplos abordados, lo que sustenta la capacidad de ofrecer sus atributos como los legítimos recursos en la generación de nuevas riquezas.

A partir de la presente investigación se propone una práctica de lectura sistémica que ayude a entender los estratos culturales generados a través del tiempo, que finalmente revele a los soportes territoriales como una única y rica resultante con espesor histórico. El conocimiento que se espera obtener sirve de base para el desarrollo socioeconómico futuro, el análisis implementado en la metodología pone de manifiesto una valoración correcta de sitios que pueden ser potenciados y explotados como atractores, a partir de nuevos argumentos empleados en la gestión del territorio y de las actividades turísticas actuales.

\section{BIBLIOGRAFIA}

ACORDINARO, N. (2009) Desde Luján. Una mirada a los sucesos mendocinos. Mendoza: Municipalidad de Luján de Cuyo

BERMAN, M. (1982) Todo lo sólido se desvanece en el aire: la experiencia de la modernidad. Buenos Aires: Siglo XXI

DÍAZ ARAUJO, E. (2003) Los Fader, empresarios del infortunio, en: Revista de la Junta de Estudios Históricos de Mendoza, $2^{\circ}$ Época, $N^{\circ}$ 6, T1 (365-392)

GÓMEZ DÍAZ FRANZÓN, A. (2011) Arquitectura del veraneo y su época en Sanlúcar de Barrameda (Cádiz) 1900-1950. Sanlúcar de Barrameda: A.S.E.H.A.

GUTIÉRREZ VIÑUALES, R. (1998) Fernando Fader: obra y pensamiento de un pintor argentino. CEDODAL, Disponible en http:// www.ugr.es/ rgutierr/PDF2/LIB\%20002.pdf

INCHAUSPE, O. Y MARZO, M. (1967) Geografía de Mendoza. Tomo 1 y 2. Buenos Aires: Ed. Spadoni SA.

LACOSTE, P. (2013) El ferrocarril Trasandino y el desarrollo de los Andes centrales argentinochilenos (1872-2013) Santiago: Ed. IDEA 
LACOSTE, P. (2004). El Ferrocarril Trasandino y la invención de la montaña como espacio social. Entrepasados, 24 (177-198).

LACOSTE, P. (1998). Grandes obras de Mendoza. Aportes para el estudio de la historia del turismo y la Ingeniería. Mendoza: Diario UNO.

LACOSTE, P. y otros (comp.) (2004) Mendoza a través de su historia Mendoza: Caviar Blue

LARRINAGA RODRÍGUEZ, C. (2007). El turismo y la ciudad de San Sebastián en la edad contemporánea. Un análisis en el largo plazo. II turismo e la cittá tra XVIII e XIX secolo. Italia e Spagna a confronto (108-126).

LARRINAGA RODRÍGUEZ, C. (2005). A Century of turismo in Northern Spain, 1815-1914. Histories of Tourism, Chanel View Press (88103).

PASTORIZA, E. (2008). El turismo social en la Argentina durante el primer peronismo. Mar del Plata, la conquista de las vacaciones y los nuevos rituales obreros, 1943-1955., en Nuevo Mundo Mundos Nuevos, Debates [En línea], Puesto en línea el 16 junio 2008. URL: http://nuevomundo.revues.org/36472. Consultado el 11 setiembre 2012.

PONTE, J. (1999) La fragilidad de la memoria. Representaciones, prensa y poder de una ciudad latinoamericana en tiempos del modernismo. Mendoza, 1885-1910. Mendoza: Ediciones Fundación CRICYT

SAUTU, R. y otros (2005) Manual de metodología. CLACSO, colección Campus Virtual, Buenos Aires.
SOBRINO SIMAL, J. (2015). Los paisajes históricos de la producción en Cuba, en Esempi di Architettura, Conservación de centros históricos en Cuba. Vol 1. 32 (225246)

TEDESCHI, E. (1972) Teoría de la Arquitectura. (3a. ed.) Buenos Aires: Ediciones Nueva Visión.

WAISMAN, M. (1972). La estructura histórica del entorno. Buenos Aires: Ediciones Nueva Visión SAIC.

WAISMAN, M. (1993). El interior de la Historia. Historiografía Arquitectónica para uso de Latinoamericanos. Bogotá: ESCALA.

\section{REVISTAS Y OTRAS PUBLICACIONES}

EMPRESA LUZ Y FUERZA (1926) Algunos datos ilustrativos sobre la nueva Usina Hidroeléctrica Cacheuta y demás instalaciones de la Empresa Luz y Fuerza SA en la provincia de Mendoza, República Argentina.

LIBRO DE ORO DE CACHEUTA (1932). Publicación de la Sociedad Anónima Termas de Cacheuta: $\mathrm{s} / \mathrm{d}$

LUZ Y FUERZA, Revista Mensual Ilustrada (período consultado: 1925 a 1929)

REVISTA MENSUAL BAP- Buenos Aires al Pacífico (período consultado: 1922 a 1930) 
88 Anales de Investigación en Arquitectura Vol.9 (2), 2019. Montevideo (Uruguay), 69-88 Universidad ORT Uruguay - ISSN 2301-1513 (en línea) 